\title{
An Enhanced QFD Approach for Improving Water Tanks Sustainability at a Local Water Distributor
}

Raid Al-Aomar*, Jassem Al-Dhanhani and Salem Al-Ali

Master of Engineering Management Programme, College of Engineering \& Computer Science, Abu Dhabi University, UAE

\begin{abstract}
Purpose: This paper utilizes a modified version of Quality Function Deployment (QFD) and the House of Quality (HOQ) in enhancing the technical requirements of constructing water tanks at a local water distribution company in Abu Dhabi and in developing a viable/sustainable solution to water leakage problem. Reported tanks problems negatively affect the company in terms of increased costs of maintenance and water losses and reduced customer satisfaction which hinders water sustainability and consumes company resources.
\end{abstract}

Design/methodology/approach: A customer-driven approach is followed to identify internal and external customer needs, construct the QFD-HoQ, and develop feasible technical solutions to existing water tanks problems. To this end, surveys were used to collect data from internal and external customers. The data is analyzed to identify the specific needs of customers and use them as an input to construct the $\mathrm{HoQ}$ along with their ranking of relative importance. However, the standard QFD approach is adapted to fit the nature of the problem and the needs of the study. A complete HoQ is developed to translate customer needs into specific set of technical requirements tank standards. The results obtained from the complete $\mathrm{HoQ}$ are then analyzed to set a technical solution and an action plan.

Findings and originality/value: Applying the proposed method at the local water distribution company in Abu Dhabi has resulted in enhancing the standards of constructing the currently used tanks (RCC and Steel types) by setting targets/changes to 16 technical requirements. These technical requirements meet 6 identified categories of customer needs in terms of tanks durability, leakage, quality, assembly, maintenance, and cost. The results analysis has also led to proposing a solution alternative for replacing the old RCC and Steel tanks by GRP tanks wherever possible. Such results benefit both the customer (in terms of better service and higher satisfaction) and the company (in terms of reduced cost and more effective operations) and improve the sustainability of water resources on the long run.

Research limitations/implications: The project was limited by the data collection and access to specific technical information of water tanks. This is mostly related to tanks location, exact amount of water leakage, and tanks design and technical specifications. A team of subject matter experts is, therefore, consulted when developing the technical solutions in response to certain customer needs. The Also, the study was limited by difficulties in gaining the access to the remote areas of external customers. Surveys were emailed to these locations instead of having face-to-face interviews.

Practical implications: The proposed approach showed how to practically integrate the generic needs/expectations of external customers with the technical requirements of internal customers in departments such as operations, maintenance, and asset management and how to develop an action plan that meets the needs of both sides. This method can be utilized by other 46 water distribution companies to improve the sustainability of their water tanks, to minimize any unnecessary spending, and to solve problems reported by customers. Utilizing QFD as an important tool of Total Quality Management (TQM) can also pave the way in the future to exploit more TQM practices in water distribution companies towards achieving organizational excellence.

Social implications: Reducing water waste and improving the sustainability of water tanks and networks is getting more attention in many societies. This is particularly important in the Gulf States where water resources are scares and the cost of water desalination is high and consumes significant energy.

Originality/value: The approach emphasizes the importance of utilizing QFD in selecting technical solution alternatives based on customer voice. It addresses the costs of poor quality or hidden costs which are typically ignored in standard QFD applications. The approach also integrates several quality tools and graphical techniques into the standard QFD approach.

Keywords: Total quality management; Quality function deployment; Cost of poor quality; Quality tools; Water distribution network; Water sustainability

\section{Introduction}

Many organizations, companies, and firms are increasingly adopting Total Quality Management (TQM) tools and methods to enhance customer service, increase operational effectiveness, and improve quality. As discussed in Goetsch and Davis [1], a key principle of TQM is to be customer-focused when developing new products/services as well as when enhancing existing ones. Many models and frameworks of business excellence were developed based on key principles of TQM. The EFQM Excellence ModelR is one of the most popular business excellence models amongst organizations in Europe and around the world (EFQM).
Similarly, quality awards such as the Malcolm Baldrige National Quality Award (MBNQA) in the US were developed to improve performance, implement TQM, and achieve organizational excellence.

*Corresponding author: Al-Aomar R, Associate Professor, Master of Engineering Management Programme, College of Engineering \& Computer Science, Abu Dhabi University, UAE, E-mail: raid.alaomar@adu.ac.ae

Received March 06, 2013; Accepted May 02, 2013; Published May 08, 2013

Citation: Al-Aomar R, Al-Dhanhani J, Al-Ali S (2013) An Enhanced QFD Approach for Improving Water Tanks Sustainability at a Local Water Distributor. Ind Eng Manage 2: 113. doi:10.4172/2169-0316.1000113

Copyright: (c) 2013 Al-Aomar R, et al. This is an open-access article distributed under the terms of the Creative Commons Attribution License, which permits unrestricted use, distribution, and reproduction in any medium, provided the original author and source are credited. 
Quality Function Deployment (QFD) is a widely used TQM tool for translating the Voice of Customer (VOC) into technical and non-technical features and functions that meet or exceed customer expectations. It is a customer-driven improvement planning tool that helps various enterprises to understand the wants/needs of customers and find out possible means to accomplish them efficiently and effectively. QFD was first developed in Japan in the late 1960s as a tool for integrating quality into the development of products and services [2]. QFD applications include enhancement of products and services of companies in many industries. Details of QFD application to real-world problems can be found in Bossert [3]. An extensive review of QFD literature can be found in Chan and $\mathrm{Wu}$ [4]. Throughout the years, the QFD method has significantly developed and was widely implemented for developing products and services in both industrial and service sectors. Each new QFD application often presents an opportunity for practitioners to explore other areas where the QFD concept could be used.

The issues related to resources sustainability and the environmental concerns are getting more attention from companies and government entities in many countries. For example, many manufacturers are enhancing their strategies and operations to be more sustainable and environmentally conscious [5]. The focus of organizations nowadays leans more towards the sustainable development of products and services [6]. Utility companies in particular have a special responsibility in this regard when acquiring and distributing critical resources such as water, gas, and electricity to consumers. Sustainable water distribution and storage is a key contributor to the resources sustainability and to the public health [7]. Typical issues in this regard include water leakage, availability, and quality. Such attributes are highly affected by water tanks specifications and maintenance. For example, Novo et al. [8] presented a review of seasonal heat storage in large basins (water tanks and gravelwater pits). Mahfouz et al. [9] studies the impact of water chlorination in domestic storage tanks on childhood diarrhea. QFD can be utilized to incorporate the consumer complaints and expectations in enhancing the specifications of water tanks and standards of their construction and increate improve the overall sustainability of water storage and distribution. QFD application in sustainability studies is one of the latest growing areas of research [10]. The focus in such studies is to enhance the QFD approach so that it accommodates the sustainability needs related to the utilization of resources and the development of products and services. This is noticeable in the QFD applications to design for recycling, green products and technology development, and green supply chains. For example, Vinodh and Chintha [11] presented an application of fuzzy QFD for enabling sustainability in an Indian modular switches manufacturer. Other examples of QFD sustainability applications can be found in Masui [12]. In this paper, QFD is used since the study is mainly focused on the incorporating the voice of the customer in an organizational effort towards implementing TQM principles and achieving a long term customer satisfaction. The study reassert the fact that QFD is one of the main pillars of achieving successful TQM that is expected to pave the way to customer satisfaction (internal and external). This is also expected to help the company to be more efficient and to self-sustain a more effective cost cutting strategy on the long run. The study utilizes QFD to improve the sustainability of water tanks in a local water distribution company in Abu Dhabi. In general, water resources are becoming more limited by time and in many countries. Thus, the sustainability of water tanks and distribution networks has been emphasized in many societies. In Gulf States, where water desalination is costly, sustaining water resources is even more crucial. Water tanks construction and technical specifications play a key role in this regard. The use of higher quality water tanks can significantly reduce the cost of poor quality in terms of the following:

\section{Inspection cost}

\section{Reworks in case of defects}

\section{Development cost of failed tanks}

\section{Excessive overtime in case of emergencies}

\section{Cost of wasted water in case of spillage or flooding}

From a quality engineering perspective, these costs can be categorized as Cost of Poor Quality (COPQ) to emphasize the TQM contribution to the economic performance of an organization [13]. In the context of water distribution, these costs can be also viewed as an organizational effort towards sustainable development and increased social responsibility, as discussed in Isaksson [14]. Thus, water is often viewed as a valuable commodity to the company as well as to the society. Rogers et al. [15] presented different ways to promote equity, efficiency and sustainability in the water sector using water pricing. Other studies that highlight the COPQ in water distribution include Farmani et al. and Sorgvist [16-17].

The objective of the study is to develop and action plan based on the declared or implicit customer concerns and needs while reducing water waste and the growing cost of water tanks operations and maintenance. The plan should include specific technical recommendation to improve the construction of the currently used two types of tanks (RCC and Steel) and checking the viability of replacing old tanks with a new type (GRP tanks). QFD is selected as an approach to achieve study objectives. The importance of this approach is that it will benefit both the customer and the company on the long run. The company is emphasizing on cutting cost in the long run to achieve a self-sustaining organization in the face of economical squalls.

\section{Quality function deployment}

QFD is simple terms is a critical aspect of the process of building quality into the product. As presented in Akao, [18] QFD aims at delivering products and services that efficiently satisfy customers. It is a key step towards total quality as it intends to build the quality that is desired by the customer into the product and services from the very beginning. Another advantage of QFD is the opening of several communication channels between different departments to collectively work on designing or enhancing a product or a service that meets customer expectations and minimizes the costs of poor quality. As discussed in Bouchereau and Rowlands, [19-20] QFD provides a visual connection to help development teams focus on the needs of customers.

QFD translates the Voice of Customer (VoC) or customer needs (the WHATS) into its means of accomplishment (the HOWS). In tangible products, this often includes the translation of desirable qualities into product technical and non-technical features and functions. In services, QFD focuses on process enhancements and service improvements. The $\mathrm{VoC}$ includes the declared and even hidden customers' needs. It can be captured through questionnaire, observation, open sessions, social media, and so many other ways. For cases where customers are professional bodies, other organizations, or regulators, questionnaire and brain storming sessions are highly recommended. Based on the VoC, actions are set to enhance the product/service so that the new design/model meets or exceeds customer needs and expectations. This can be accomplished incrementally or at one step based on technical difficulty and the available time and cost. 


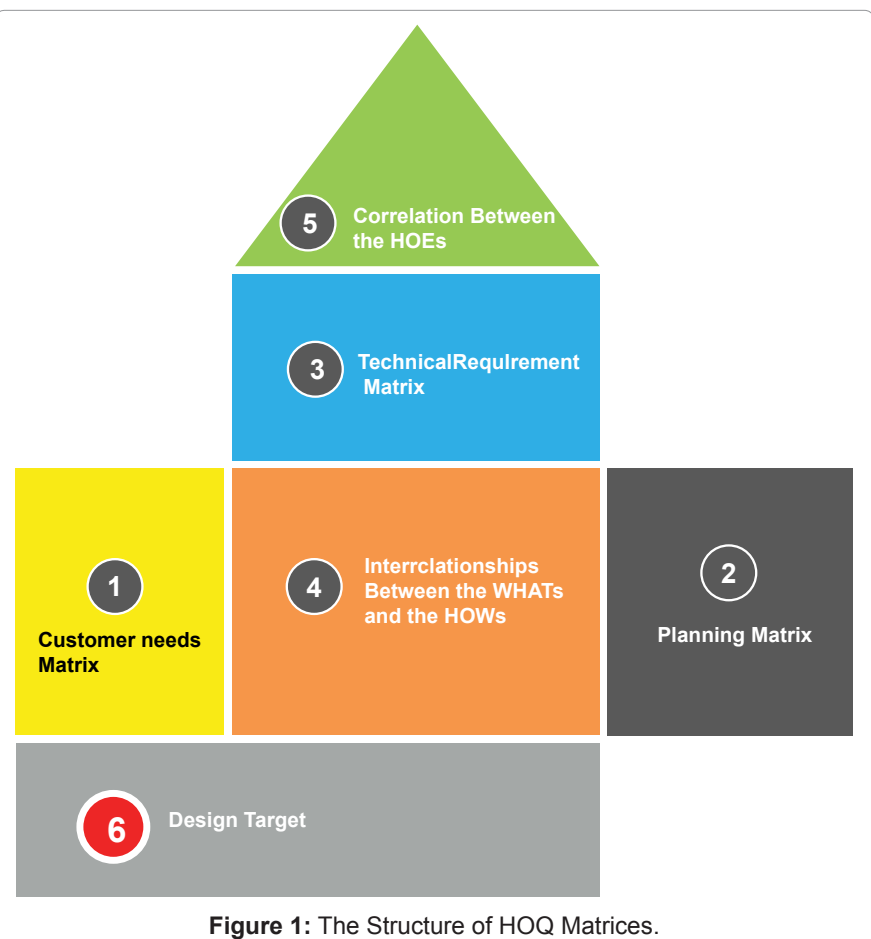

The HoQ is the graphical summary or structure of QFD. It consists of a set of different matrices that are linked together to arrive at an effective design/enhancement to the underlying product/service. As shown in Figure 1, these matrices are as follows:

1. Matrix No. 1: Customer needs (WHATs)

2. Matrix No. 2: The planning or the product/service improvement strategy

3. Matrix No. 3: Technical requirement (HOWs)

4. Matrix No. 4: The Interrelationships between the WHATs and the HOWs

5. Matrix No. 5: The direction of correlation between the HOWs

6. Matrix No. 6: The design target (values) of the HOWs

In this paper, we will be primarily using the QFD-HoQ to embed 209 the VoC in the design/replacement of the currently used RCC and steel tanks in a local water distribution company in Abu Dhabi. To this end, the standard QFD structure is adapted to fit the nature of the underlying problem. The following sections present the used QFD methodology and the results of applying the methodology to reduce the water leakage. Results of QFD application are then analyzed and the benefits of the proposed approach are discussed.

\section{Enhanced QFD Methodology}

A simple yet effective research methodology is followed in order to utilize QFD for reducing water leakage and improving water sustainability. The methodology is based on adapting the standard QFD approach and on integrating quality tools such as Pareto analysis and fishbone diagram into the QFD methodology. Other tools utilized in the solution include affinity and tree diagrams. Sessions of brainstorming were also conducted by design team to identify and set targets to the solution technical requirements.
The following methodology is followed to adapt the standard QFD and develop the six matrices needed to construct the HoQ:

1. Matrix No. 1: Customer needs (WHATs)
a. Gathering customer needs input
b. Refining the customer needs input
c. Using the affinity diagram
d. Using the tree diagram
e. Acquiring customers' ranking (relative importance)

2. Matrix No. 2: The planning/improvement strategy
a. Competitive benchmarking
b. Planned customer satisfaction performance
c. Improvement factors

3. Matrix No. 3: Technical requirements (HOWs)

a. Specialized design team work

4. Matrix No. 4: Interrelationships between the WHATs and the HOWs

a. Specialized design team work

5. Matrix No. 5: Direction of correlation between the HOWs

a. Specialized design team work

6. Matrix No. 6: Design target (values) of the HOWs
a. Technical priorities
b. Technical benchmarking
c. Setting design targets

The following is a detailed description of the used QFD approach to construct the matrices of the HoQ:

\section{Matrix 1: Customer needs (WHATs)}

Investigating customer needs: The first step to develop this matrix is to identify the customers and to investigate their needs "WHATs". To this end, two approaches are followed; surveys and face to-face interviews. Surveys and questionnaires were first used to identify the requirements of the O\&M and asset management representatives. One-to-one interviews were then used to give better understand the customers' need and give the chance to clarify their requirements. External VIP customers and residents of remote islands were approached for feedback via surveys only as it was hard to arrange for face-to-face interviews.

Pareto analysis: The data acquired from the surveys collected from customers were organized in check sheets and summarized in Pareto charts to identify the vital few problematic elements or issues that need focus in the currently used RCC and Steel tanks. The 80-20 rule is used to distinguish the vital few from the trivial many tanks issues.

Affinity diagram: This project management tool has allowed the team to sort ideas developed in the face-to-face interview sessions with the customer to be ready for the first matrix of the HoQ. This tool has also allowed the team to categories customers' concern in a logical manner that is simple to understand and utilize in the later decisions.

Tree diagram: Explain how used in the project. 
Customer importance: This step aims at ranking the key factors/ issues identified and filtered from the surveys and face-to-face meetings. A ranking scale from 1-5 is used by the customers to set their relative importance of the identified factors.

\section{Matrix 2: Planning/improvement strategy}

This matrix is typically used by designers to plan the needed improvement in the underlying product/service, in this case the water tank. Some of the values are estimated by the design team and others are calculated. Estimated values include the planning Customer Satisfaction (CS) rating and the Sales Point (SP) improvement level. CS rating sets the targets at which we would like to see the level of customer satisfaction while SP estimates the expected impact on improving sales or satisfaction of customers. Based on CS and SP, the WHATs improvement factors that will be considered in the selection and design of different tanks alternatives will be calculated as follows:

Improvement factor $=([$ Planned CS Rating-Existing CS Rating $]$ $\mathrm{x} 0.2)+1$

Then, the overall weighting of each customer WHAT is calculated as follows:

Weighting $=$ Customer importance $\mathrm{x}$ Improvement factor $\mathrm{x}$ Sales point

Finally, the percentage of Total Weighting is calculated as follows:

$\%$ of Total Weighting $=($ overall weighting $/ \Sigma$ overall weighting $)(3)$ $\mathrm{x} 100$

\section{Matrix 3: Selecting the technical requirement (HOWs)}

This step shows how the specialized design team responded to each of the customer needs WHATs. To this end, a specialized team of tanks experts studies the identified customers' "WHATs" and explored the technical requirements of the tank that are expected to meet or exceed these customer needs. Brainstorming sessions were organized by the team to generate ideas for tanks improvement and to explore potential changes in tanks design and material.

Brainstorming: This well-known creative problem-solving technique is based on forming a team of mixed knowledge and creating a comfortable environment for the team to generate design and improvement ideas. A systematic approach is followed to encourage the team members to create ideas and to filter these ideas and select those that are innovative and economically viable.

\section{Matrix 4: Evaluating interrelationships between the WHATs and the HOWs}

This step is aimed at identifying the relationships between customer needs "WHATs" and technique requirement "HOWs". A ranking of 1 , 3 , and 9 are typically used to assess the relationship as weak, moderate, and strong relationship, respectively. This is also performed by the team of experts as it requires deep knowledge in the product/process to be able to identify the relationship between each customer "WHAT" and all suggested technical requirements "HOWs".

\section{Matrix 5: Evaluating the direction of correlation between the HOWs}

This step examines the correlation between the different technical requirements "HOWs" that have been already developed based on the customer needs "WHATs". To this end, the impact of each technical requirement is tested on other proposed technical requirements and the correlation is assessed as direct, inverse, or none. This enables the team to better understand the relationship between different requirements and most importantly avoid contradictions and any unnecessary spikes in cost. Again, this task requires the expertise of the specialized team to be able to identify such explicit or implicit impacts amongst technical requirements.

\section{Matrix 6: Selecting the design targets (values) of the HOWs}

The last matrix in the HoQ is aimed at setting values (quantitative or qualitative) to the selected technical requirements "HOWs". The values are set by the design team and should be approved by management for implementation. Priorities need to be set in the typical situation of limited resources for implementation. To this end, technical priorities of all technical requirements "HOWs" are calculated and weighted.

Technical Priorities: The technical priority of each "HOW" determines the relative importance of the related technical requirement. The technical priority is calculated for each technical requirement (column) as follows:

Technical priority $=\Sigma$ (Relationship $\mathrm{x}$ Overall Weighting)

The percentage of total priority is calculated for each technical requirement (column) as follows:

$\%$ Total priority $=($ technical priority $/ \Sigma$ technical priorities $)$ $\mathrm{x} 100$

At the end, the identified technical priorities are put into an action plan ready for deployment based on their priority. If time and resources are available, the team can recommend implementing all technical changes to enhance the product. If not, a priority plan is set for implementation.

\section{QFD application for water tanks sustainability}

The enhanced QFD methodology was applied at a local water distribution company at Abu Dhabi. The main field of operation of the utility company is the distribution of water to the general population (households, businesses, hospitals, government buildings, and so on). One of the most important divisions within the company is the Project Division which oversees the execution of hundreds of water and power projects within and around the city of Abu Dhabi. These projects include construction of water distribution lines, valve chambers, and water tanks which represent the main focus of this paper. The initial idea behind this project is to find a replacement to the current use of Roller-Compacted Concrete (RCC) and Steel water tanks based on the customer voice (complaints, requirements, and expectations). Surveyed customers include internal customers (Operations and Maintenance (O\&M) and Asset management) as well as external customers (VIP customers, remote areas, and islands residence). Specific recommendations and actions will be taken based on the findings and results obtained from applying the QFD approach to the underlying case study. This will benefit both the customers by addressing their concerns and increasing their satisfaction as well as the company by cutting the growing costs of repairs, reducing water leakage, and improving the overall quality of its services. The following is a description of how the QFD approach is applied to the water tanks replacement project at the distribution utility company. However, and per the request of the company, the authors will withhold from disclosing any sensitive information about the location of the tanks and their design or technical specifications. Alternatively, the focus will be on applying the proposed approach to several aspects of RCC, Steel, 
and GRP (Glass-fiber Reinforced Plastic) tanks without any specific engineering details. O\&M detailed reports were used to extract data about water leakage, reported frequency of tanks maintenance, water contamination, and toxic material found in water tanks among other information. However, such information is restricted from circulation inside or outside the company. The application of the proposed QFD approach to improve the services of the water distribution company includes the following 3 major steps:

1- Gathering and analyzing customer data

\section{2- Constructing the QFD-HoQ}

3- Analyzing the results and setting an action plan

The following is a description of the steps of applying the proposed QFD approach to the water distribution company.

\section{Gathering and analyzing customer data}

The objective of this stage is to gather data essential to identifying the exact customer needs from both internal and external customers. The data and information required from customers (both external and internal) are collected as follows:

External customers: The approach application started by surveying VIP representatives and remote area residents on the following points:

- Water supply interruption

- Water quality

- Availability of alternative sources of water

- Other issues or concerns

Surveyed customers were also asked to specify the type of water tanks/source they are currently using (RCC, Steel, GRP, or direct water supply). Results of external customer survey revealed that the majority of water tank users are using RCC tanks and the customers being supplied with water from RCC tanks have the highest dissatisfaction rates due to multiple interruptions. VIP customers were observed to be extremely dissatisfied by RCC tanks water supply.

Internal customers: After diagnosing the concerns of external customers, specialists in the installation and maintenance of these tanks were interviewed to translate the external customer concerns into specific requirements or needs that can be used in construction the HoQ. As mentioned earlier, internal customers of the company specialized in tanks installation and maintenance include the departments of $\mathrm{O} \& \mathrm{M}$ and Asset Management. To this end, both departments' representatives were asked for their feedback on the following 10 tank aspects:

1. Durability

2. Water quality

3. Leakage rates

4. Repairs

5. Maintenance

6. Handling

7. Assembly

8. Cost of repair

9. Cost of construction

10. Cost of leaked water

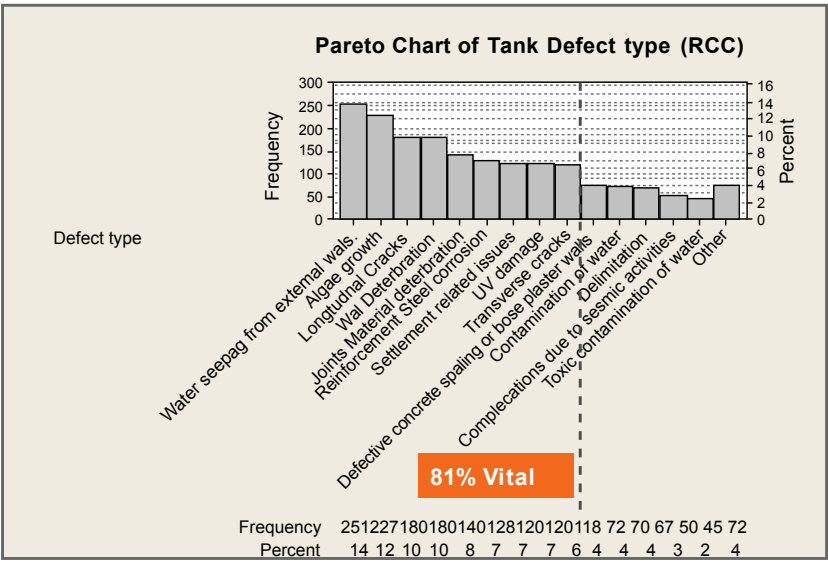

Figure 2: Pareto analysis of different RCC tank defects and issues.
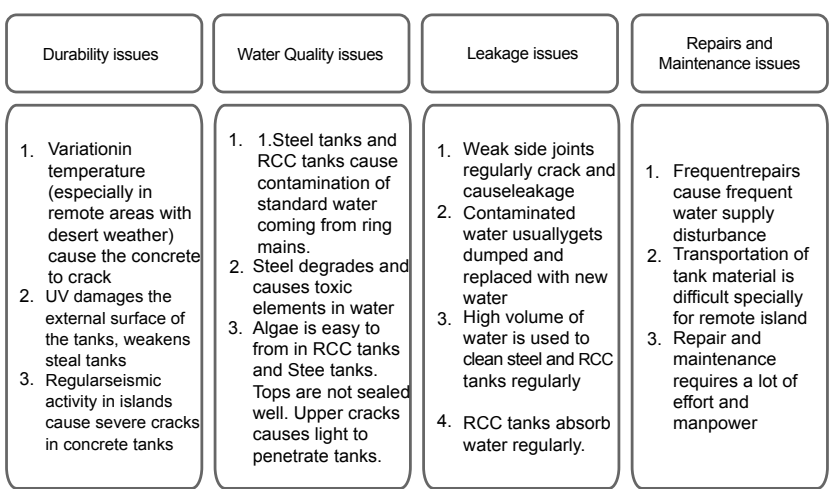

Figure 3: Affinity diagram for categorizing different tanks issues.

The focus was directed to the RCC tanks as they represent the majority of tanks used and they resulted in the most customer dissatisfaction. The asset management department has identified several concerns in this regard. For the repair and disinfection of a 500,000 MIG R.C.C tank, the loss of water is $1,000,000$ MIG per year. Since the production cost of one water gallon is about AED 0.18, the total cost of water loss is $0.18{ }^{*} 1,000,000=$ AED $180,000.00$ per year for one tank. This should be added to the cost of water leakage that is kept confidential. The cost of repair and maintenance varies depending on contract awarded. Finally, the cost of tank construction also varies, but typically for 250,000 MIG tank, it is about AED 1,400,000.00, depending on contract awarded.

The O\&M specialists were able to relate the concerns of the external customers using RCC tanks to their multiple causes. The O\&M defects $\log$ file was used to identify the frequency of each type of tank defect. Fishbone diagrams were also used to investigate the root causes of reported problems. As shown in Figure 2, a Pareto chart is developed to present the results of ranking different type of tanks defects and reported issues.

As shown in Figure 2, 9 types of tank defects represent the vital few ( $81 \%$ of total defects). This ranking will help later in setting the priorities of the action plan as it is a typical challenge for the team to address all causes of RCC and steel tank defects.

After identifying the technical causes of tanks defects and operational issues, the team conducted brain storming session to categorize different tanks defects and reported issues. As shown in 
Citation: Al-Aomar R, Al-Dhanhani J, Al-Ali S (2013) An Enhanced QFD Approach for Improving Water Tanks Sustainability at a Local Water Distributor. Ind Eng Manage 2: 113. doi:10.4172/2169-0316.1000113

Figure 3, an affinity diagram is developed to organize and report the results of the brain storming session.

The final step in this stage is to translate the reported tanks concerns into specific needs or "WANTs" that can be used in the QFD-HoQ. To this end, a set of specific needs are formulated at each identified category in the affinity diagram. Table 1 summarizes the 13 developed needs distributed at the four categories. Addressing these needs will address the issues reported by internal customers (O\&M and Asset Management) as well as external customers.

\section{Construction of the HOQ}

The construction of the QFD-HoQ is achieved by developing the 6

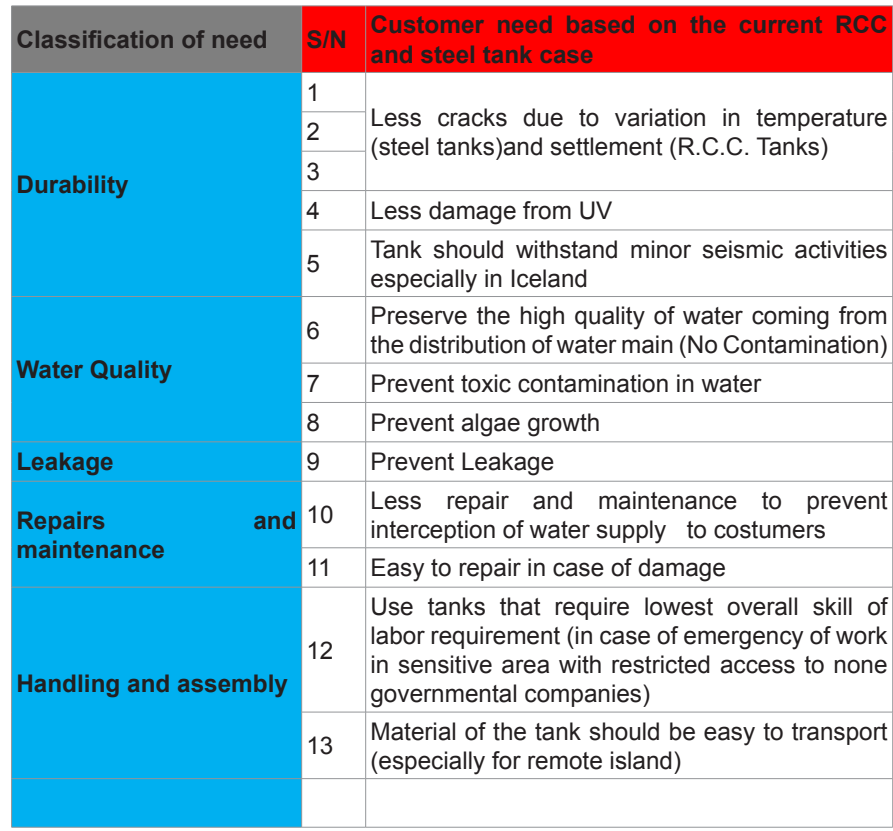

Table 1: The identified needs of internal and external customers.

\begin{tabular}{|c|c|c|}
\hline \multicolumn{3}{|c|}{ Customer Needs Matrix } \\
\hline \multirow{3}{*}{ 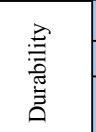 } & Less cracks due to variation in temperature & 4 \\
\hline & Less damage from UV & 1 \\
\hline & $\begin{array}{c}\text { Tanks should withstand minor seismic activities } \\
\text { especially in islands }\end{array}$ & 2 \\
\hline \multirow{3}{*}{ 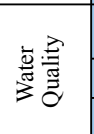 } & $\begin{array}{l}\text { Preserve the high quality of water coming from the } \\
\text { distribution water main (NO contamination) }\end{array}$ & 5 \\
\hline & Prevent toxic pollution of water & 5 \\
\hline & Prevent Algae growth & 3 \\
\hline 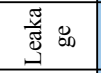 & Prevent Leakage & 5 \\
\hline \multirow{2}{*}{. } & $\begin{array}{l}\text { Less Repair and maintance to prevent interruption of } \\
\text { water supply to customers }\end{array}$ & 5 \\
\hline & Easy to repair procedure in case of damage & 5 \\
\hline \multirow{2}{*}{ 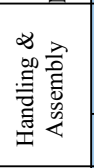 } & $\begin{array}{c}\text { Use tanks that require lowest overall skill of labor } \\
\text { requirement (in case of emergency or work in sensitive } \\
\text { area with restricted access to none governmental } \\
\text { companies) }\end{array}$ & 4 \\
\hline & $\begin{array}{c}\text { Material of tank should be easy to transport (especially } \\
\text { for remote islands) }\end{array}$ & 3 \\
\hline \multirow{2}{*}{ i } & Minimal repair and maintenance cost & 5 \\
\hline & Minimal cost of leaked water & 5 \\
\hline
\end{tabular}

Figure 4: The matrix of customer needs "WHATs".

\begin{tabular}{|c|c|c|c|c|c|}
\hline 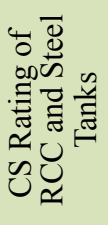 & 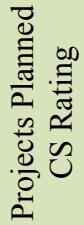 & 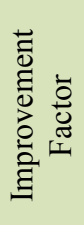 & 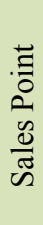 & 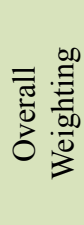 & 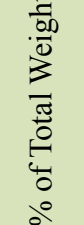 \\
\hline 2 & 5 & 1.6 & 1 & 6.4 & 8.602 \\
\hline 3 & 4 & 1.2 & 1 & 1.2 & 1.613 \\
\hline 4 & 4 & 1 & 1 & 2 & 2.688 \\
\hline 4 & 5 & 1.2 & 1 & 6 & 8.065 \\
\hline 3 & 5 & 1.4 & 1 & 7 & 9.409 \\
\hline 1 & 5 & 1.8 & 1 & 5.4 & 7.258 \\
\hline 3 & 5 & 1.4 & 1 & 7 & 9.409 \\
\hline 2 & 5 & 1.6 & 1 & 8 & 10.75 \\
\hline 1 & 4 & 1.6 & 1 & 8 & 10.75 \\
\hline 2 & 4 & 1.4 & 1 & 5.6 & 7.527 \\
\hline 1 & 4 & 1.6 & 1 & 4.8 & 6.452 \\
\hline 2 & 3 & 1.2 & 1 & 6 & 8.065 \\
\hline 2 & 4 & 1.4 & 1 & 7 & 9.409 \\
\hline
\end{tabular}

Figure 5: The planning matrix of customer needs "WHATs"

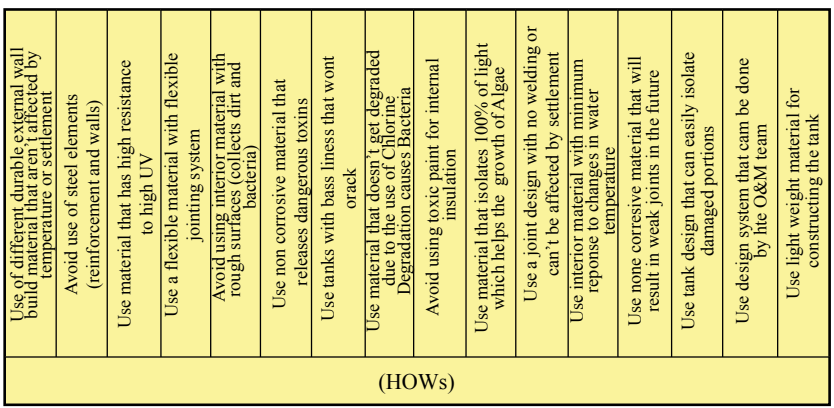

Figure 6: The technical requirements matrix "HOWs".

matrices shown in Figure 4. The following is a description of these six matrices:

Matrix 1: Customer needs matrix: This matrix is developed by listing the customer needs identified in the first stage. In addition these needs "customer WHATs" are ranked on a scale from 1-5 based on their relative importance to the customer. Figure 4 shows the customer needs matrix.

Matrix 2: The planning matrix: Using the calculations discussed in the methodology section, the planning matrix is developed and the improvement factor and relative importance weights were set for each customer need "WHAT". Figure 5 shows the filled planning matrix

Matrix 3: Technical requirement matrix: This matrix presents the team response (HOWs or technical solutions) to the identified customer needs "WHATs". To this end, the specialized team has set specific design/process changes that, when implemented, meet the customer requirements in solving the issues of RCC and steel tanks. Several brain storming sessions and discussions were conducted to arrive at these technical solutions (action plan). The team was able to identify 16 technical solutions in response to the 13 identified needs/ issues. Figure 6 shows the technical requirement matrix (Figure 6). The technical requirements matrix "HOWs" 
Citation: Al-Aomar R, Al-Dhanhani J, Al-Ali S (2013) An Enhanced QFD Approach for Improving Water Tanks Sustainability at a Local Water Distributor. Ind Eng Manage 2: 113. doi:10.4172/2169-0316.1000113

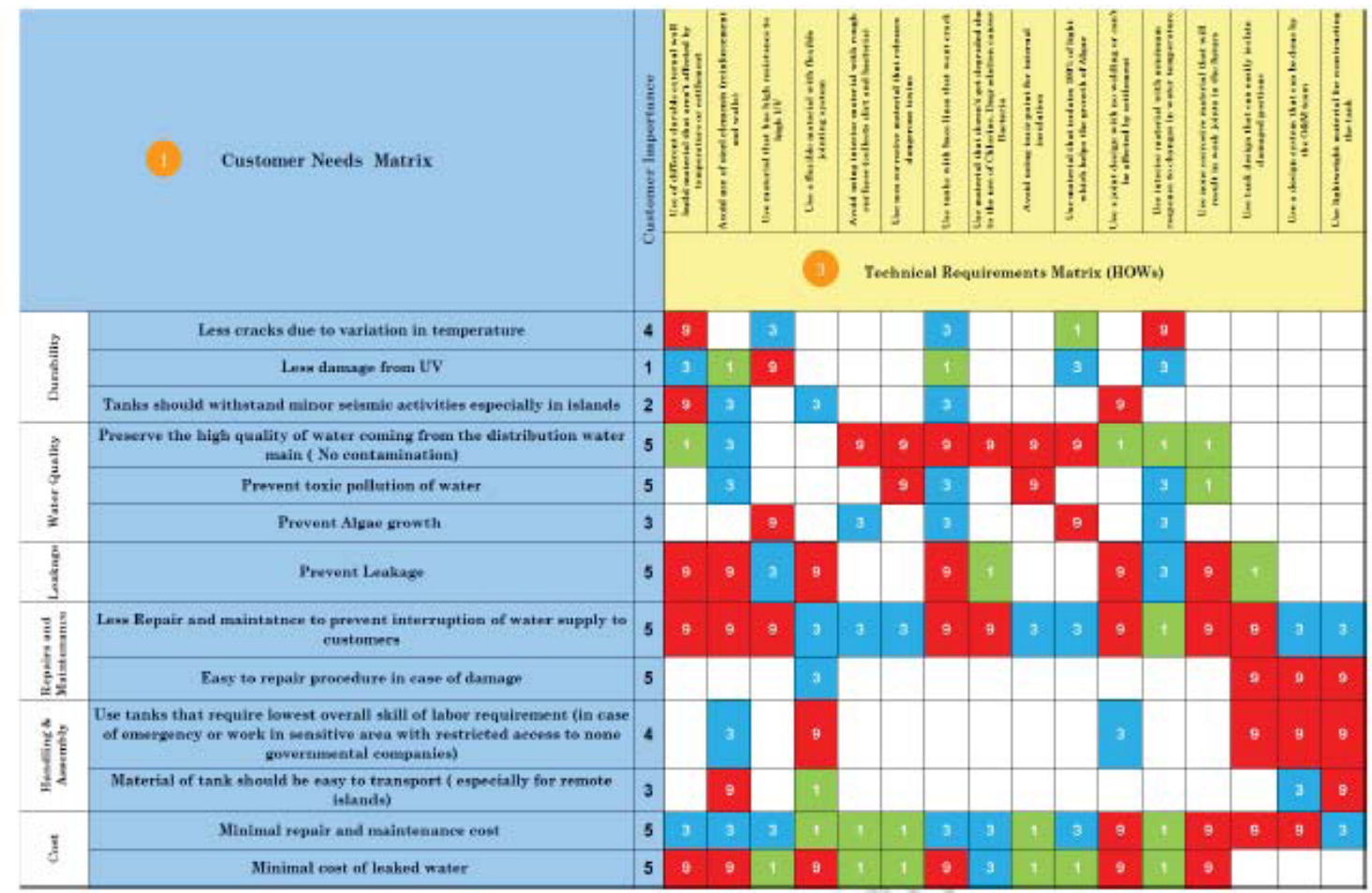

Figure 7: The WHATs versus HOWs interrelationship matrix.

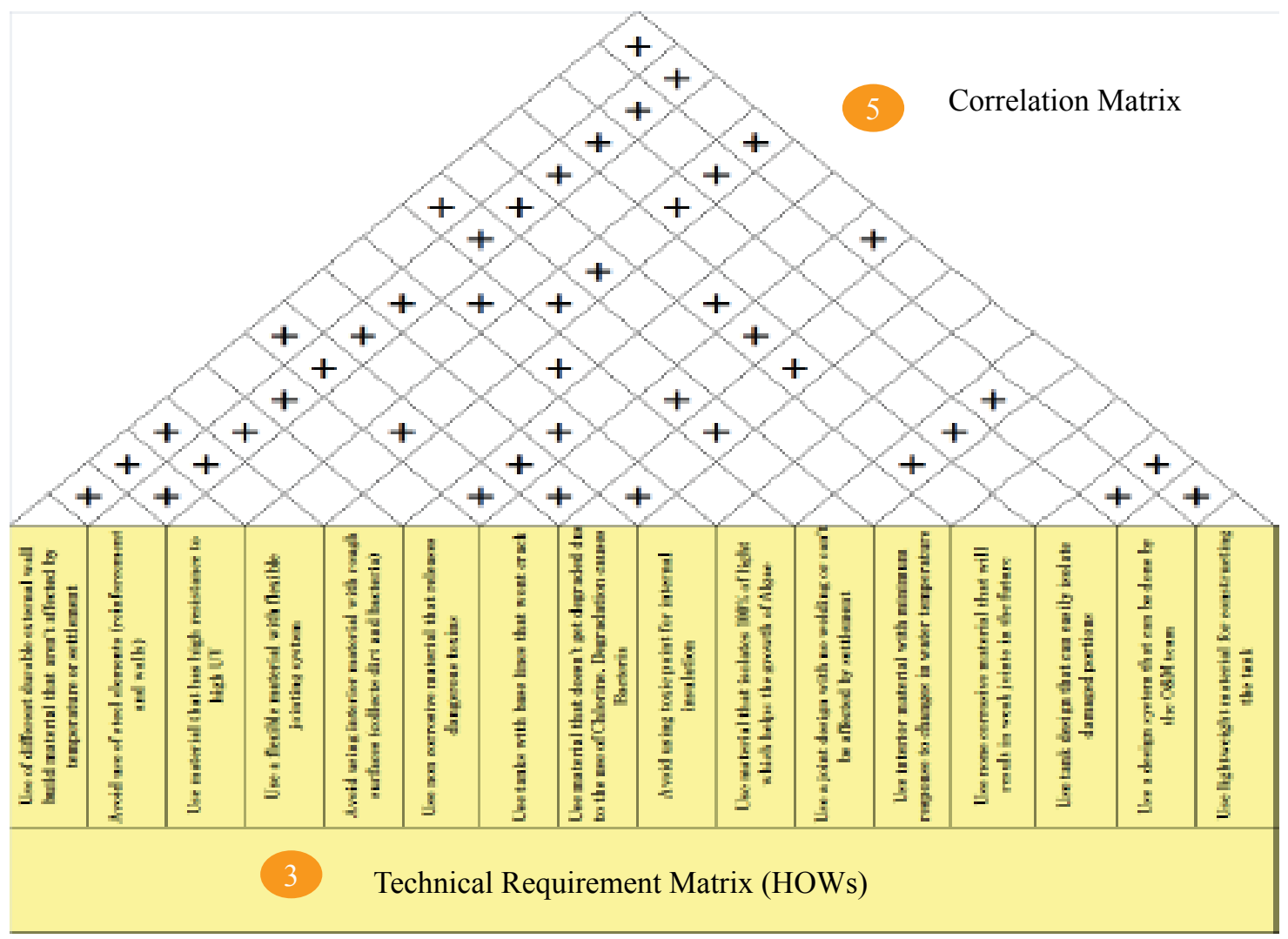

Figure 8: The technical requirements correlation matrix. 
Citation: Al-Aomar R, Al-Dhanhani J, Al-Ali S (2013) An Enhanced QFD Approach for Improving Water Tanks Sustainability at a Local Water Distributor. Ind Eng Manage 2: 113. doi:10.4172/2169-0316.1000113

Page 8 of 10

Matrix 4: WHATs vs. HOWs interrelationship matrix: As discussed earlier, this matrix illustrates the interrelation between the set technical requirements "HOWs" and the identified customer needs "WHATs". As shown in Figure 7, the interrelation is expressed in terms of a number and a color that indicate the strength of relationship between each WHAT and its relevant HOWs. The red color (level 9) indicates a strong relationship while the green color (level 1) indicates
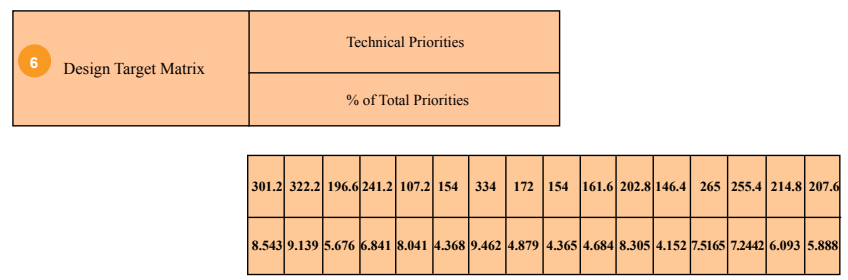

Figure 9: The design target matrix. a weak relationship. The blue color (level 3) indicates a medium relationship. Empty cells indicate no relationship. The matrix shows that each customer WHAT "row" is addressed by one or more technical requirement "HOW or column".

Matrix 5: Technical requirements correlation matrix: This matrix identifies any contradiction or conflict amongst technical requirements. To this end, correlation is expressed in the roof matrix as positive or negative, or does not exist. Figure 8 shows the technical requirements correlation matrix of the underlying case study where no contradiction or conflict is identified (only positive or no correlation exists).

Matrix 6: Design target matrix: The last matrix in the HoQ set specific design targets to the technical requirements and the priority for their implementation in the action plan. The team sets the design targets that make sure that the customer needs are addressed efficiently.

Priorities are then calculated based on the procedure explained in the methodology section. Figure 9 shows the design target matrix.

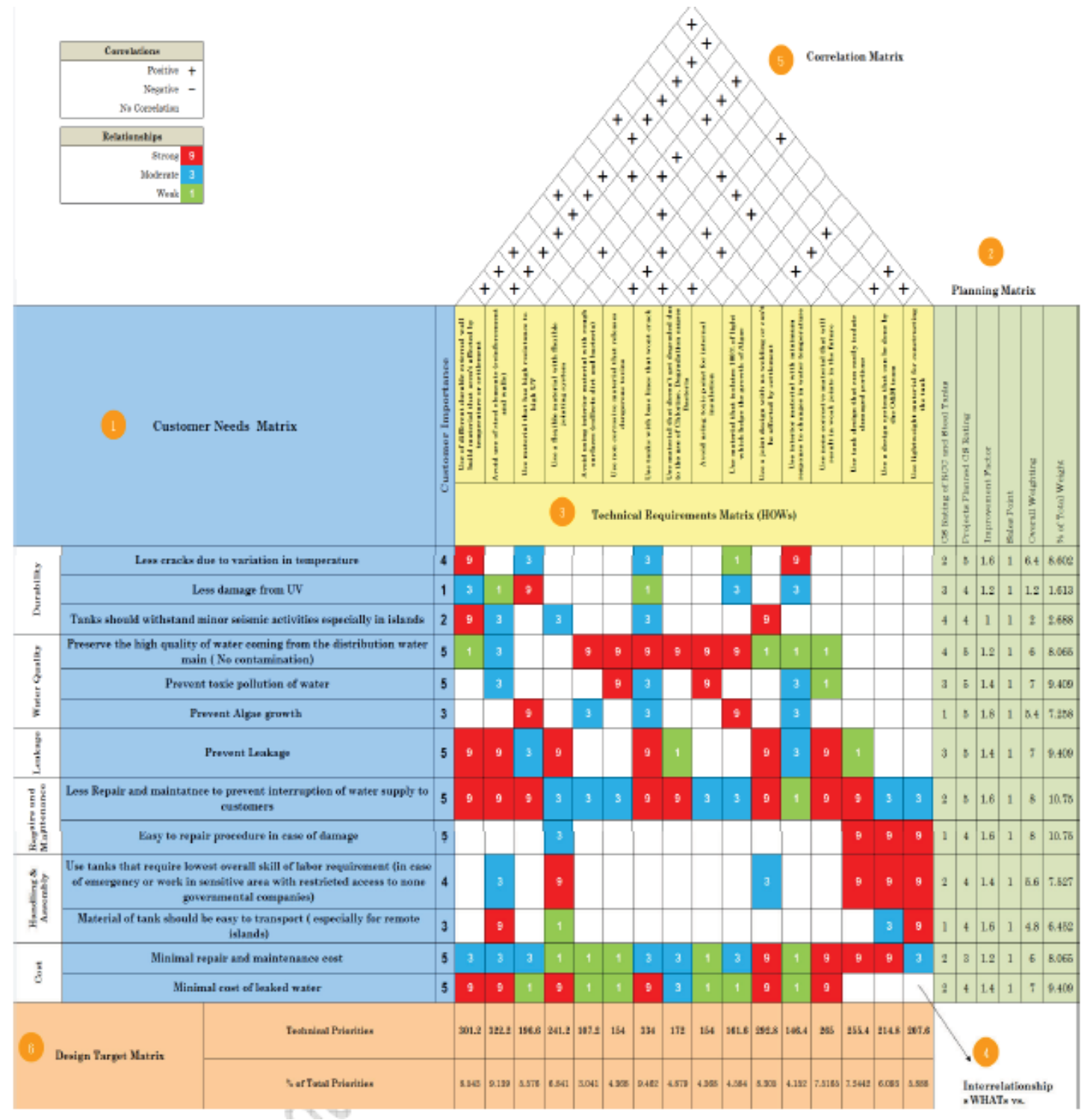

Figure 10: The developed QFD-HoQ. 
Citation: Al-Aomar R, Al-Dhanhani J, Al-Ali S (2013) An Enhanced QFD Approach for Improving Water Tanks Sustainability at a Local Water Distributor. Ind Eng Manage 2: 113. doi:10.4172/2169-0316.1000113

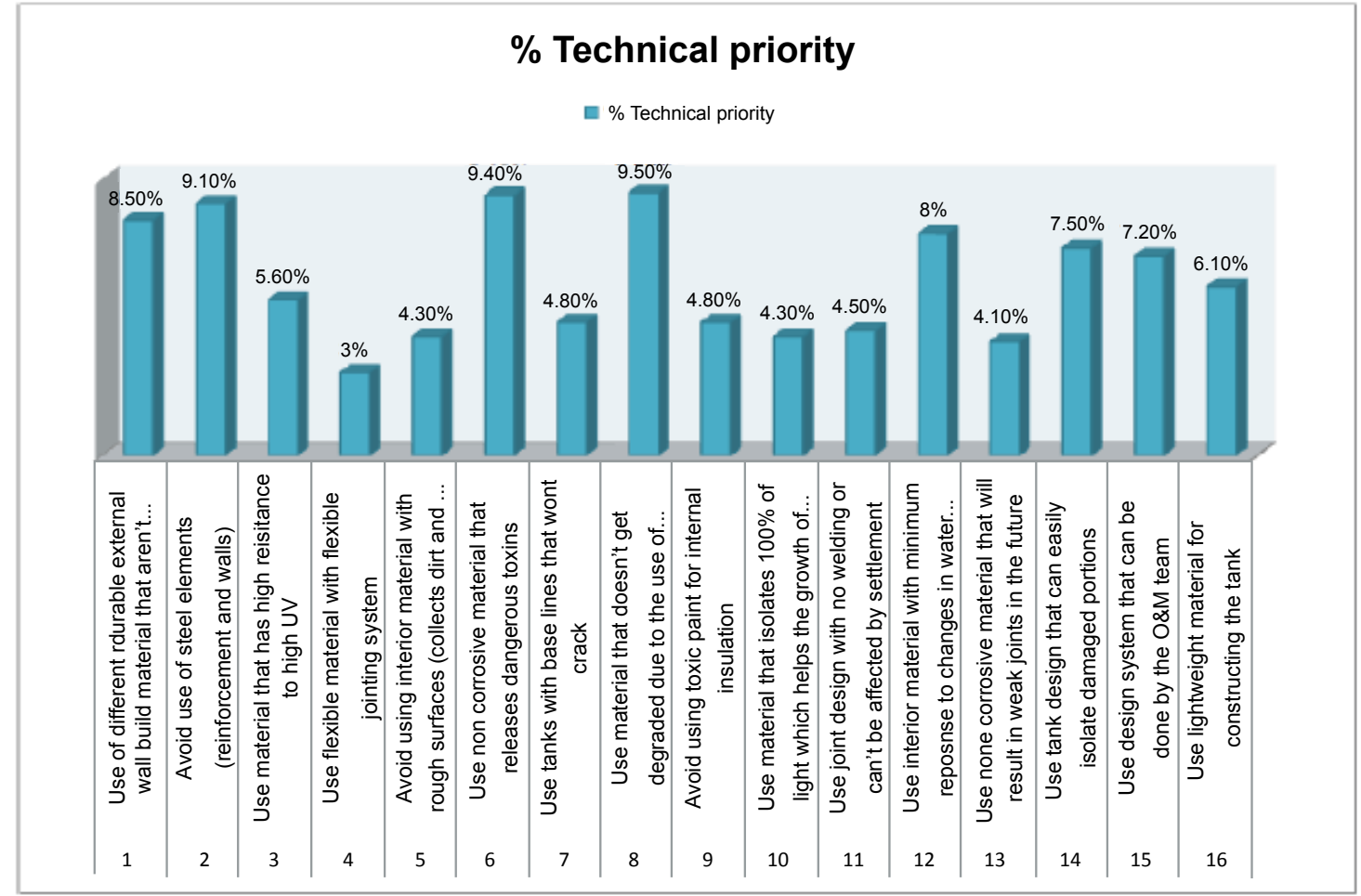

Figure 11: The priority of 16 tank technical requirement.

\begin{tabular}{|c|c|c|c|c|c|c|}
\hline $\begin{array}{l}\text { Classification } \\
\text { Need }\end{array}$ & of & CN S/N & $\begin{array}{l}\text { Customer need based on } \\
\text { the current Steel Tanks } \\
\text { case }\end{array}$ & TR S/N & $\begin{array}{l}\text { Technical Requirement that } \\
\text { will solve the issue }\end{array}$ & How can GRP solve this issue \\
\hline \multirow[b]{5}{*}{ Durability } & & 1 & \multirow{3}{*}{$\begin{array}{l}\text { Less cracks due to vacation } \\
\text { in temperature (steel } \\
\text { tanks) and settlement } \\
\text { (R.C.C tanks) }\end{array}$} & \multirow{2}{*}{$\begin{array}{l}1 \\
2\end{array}$} & $\begin{array}{l}\text { Use of different durable wall build } \\
\text { material that are not affected by } \\
\text { temperature or settlement }\end{array}$ & $\begin{array}{l}\text { Hot Pressure fiber glass reinforced panels compound at } 150 \text { degrees } \\
\text { C and } 100 \mathrm{Kg} \text { pressure produces uniform flexible panels that are not } \\
\text { affected by external temperature or settlement resistant to UV. }\end{array}$ \\
\hline & & 2 & & & \multirow{2}{*}{$\begin{array}{l}\text { Avoid use o steel elements } \\
\text { (reinforcement and walls) that } \\
\text { lead to corrosion and lead to } \\
\text { deformation of the structure }\end{array}$} & \\
\hline & & 3 & & 3 & & \\
\hline & & 4 & & 4 & $\begin{array}{l}\text { Use material that is the high } \\
\text { resistance to high UV }\end{array}$ & $\begin{array}{l}\text { The panels with stand high UV and the together of the design is } \\
\text { reflective to UV rays }\end{array}$ \\
\hline & & 5 & $\begin{array}{l}\text { Tanks should withstand } \\
\text { minor seismic activities } \\
\text { especially in island }\end{array}$ & 5 & $\begin{array}{l}\text { Use a flexibility material with } \\
\text { flexible jointing system (RCC } \\
\text { has low seismic tolerance) }\end{array}$ & $\begin{array}{l}\text { Panels has higher tolerance to seismic activities due to flexible } \\
\text { panel and joints }\end{array}$ \\
\hline
\end{tabular}

Table 2: Analysis of two solution alternatives to enhance tank durability.

At the last stage of $\mathrm{HoQ}$ construction, the 6 developed matrices are integrated together into a QFD-HoQ. Figure 10 shows the final picture of the developed QFD532 HoQ. As described earlier, the HoQ summarizes the process of translating customer needs into specific design changes and technical requirements that are expected to solve the reported tanks issues and recommend solutions to water leakage.

\section{Results and Analysis}

The project objective was initially to reduce water leakage from tanks and increase sustainability by enhancing the technical standards used by the local water company in the construction of R.C.C and Steel tanks. To this end, the team has analyzed the results of the HoQ and translated them into an action plan that, when implemented, will enhance the standards of tanks construction. Based on the results obtained from the HoQ, the team has recommended the enhancement of 16 technical requirements in the tanks construction. These technical requirements along with their technical priorities are shown in Figure 11.

These technical requirements were validated by the design team and subject matter experts from both O\&M and assets management departments. Based on their priority, the implementation plan of these requirements was set to take place in the following three phases:

PHASE 1: Focus on technical requirement with $5-10 \%$ priority

PHASE 2: Focus on technical requirement with $<5 \%$ priority

PHASE 3: Keep improving standards afterwards continually

Implementing all the recommended changes to all existing RCC and Steel tanks may not be feasible, especially for old tanks. As it was evident in the results analysis, the enhancement of their standards wasn't sufficient to meet all customer needs. Thus, the team has also developed an alternative plan to enhancing the 16 technical requirements of the 
Citation: Al-Aomar R, Al-Dhanhani J, Al-Ali S (2013) An Enhanced QFD Approach for Improving Water Tanks Sustainability at a Local Water Distributor. Ind Eng Manage 2: 113. doi:10.4172/2169-0316.1000113

Page 10 of 10

RCC and Steel tanks. This alternative is to replace RCC and Steel tanks by GRP tanks. The two alternatives were analyzed and compared based on both technical and financial aspects. Table 2 shows how the two alternatives address or approach the identified problems (customer needs) at the durability category. The same approach is followed at all other five categories (quality, leakage, repair, handling, and cost).

After studying the technical and financial feasibility of the two solutions, the team has recommend to enhance the technical features of the relatively new existing RCC and Steel tanks and to start replacing old ones with GRP tanks as they meet customer needs and save cost on the long run. RCC and Steel tanks have several limitations related to their material including the interaction with chlorine and the Ultra Violet impact on external walls, temperature, and water.

In terms of costs, current prices indicate that constructing GRP tanks is cheaper than RCC tanks. The average cost of constructing an RCC tank with 200,000 MIG is about AED 2,400,000.00 while the average cost of constructing a GRP tank with 250,000 MIG is about AED 1,400,000.00. Also and according to the information obtained from O\&M, an RCC tanks with a service life of 15 years and above are drained every year for flushing and dis-infection. In each flushing, the tank is emptied twice, once for repair of any defects and the second time for flushing and disinfection. Therefore, when considering the repair and disinfection of a 500,000

MIG RCC tank, the loss of water is 1,000,000 MIG per year. As mentioned earlier, and since the production cost of one water gallon is about AED 0.18, the total cost of water loss is $0.18 \times 1,000,000=\mathrm{AED}$ $180,000.00$. This is in one year and only for one RCC tank

\section{Conclusion}

In this paper, an enhanced version of QFD is utilized within the framework of TQM to improve the sustainability of water tanks at a local water distributor in Abu Dhabi. Current status has resulted in multiple costs and wastes that have significantly increased the company's COPQ in water storage and distribution. The approach adapted the standard QFD approach to fit the nature of the underlying company and the type of application. To this end, the voice of both internal and external customers was extracted and transformed into a specific set of technical needs. Pareto analysis and affinity diagram were used to categorize customer needs and structure the QFD-HoQ. The focus was primarily on addressing issues related to water leakage and quality, tanks durability, repair, and maintenance and the total cost. Brain storming sessions were used to identify technical solutions and set an applicable action plan (technical enhancements and better tanks construction standards). In addition to improving the sustainability of the precious water supplies, expected results include significant savings in the COPQ, more effective operation and maintenance, and improved service and customer satisfaction. A similar study can be directed to addressing the issues of water distribution networks in the same company as well as in other water distributor and the utility companies in general.

\section{References}

1. Goetsch D, Davis S (2013) Quality Management for Organizational Excellence Introduction to Quality. New Jersey: Pearson.

2. Mizuno S, Akao Y (1994) QFD: The Customer-Driven Approach to Quality Planning and Deployment. Asian Prod Org.

3. Bossert JL (1991) Quality function deployment. A practitioner's approach Milwaukee: ASQC Quality Press.

4. Chan L, Wu ML (2002) Quality Function Deployment: A Literature Review. Eur $\mathrm{J}$ of Operational Research, 143: 463-497.

5. Davies A (2012) Achieving sustainability in manufacturing via organizational and operational learning. Int J Sustain Eng 5: 135-144.

6. Keoleian GA, Menerey D (1994) Sustainable Development by Design: Review of Life Cycle Design and Related Approaches. Air and Waste, 44: 645-668.

7. Gundry S Conroy R, Wright J (2003) A systematic review of the health outcomes related to household water quality in developing countries. J Water Health 2 : $1-13$.

8. Novo AV, Bayon JR, Castro-Fresno D, Rodriguez-Hernandez J (2010) Review of seasonal heat storage in large basins: Water tanks and gravel-water pits. App Ene 87: 390-397.

9. Mahfouz AA, Abdel-Moneim M, Al-Erian RA, Al-Amari OM (1995) Impact of chlorination of water in domestic storage tanks on childhood diarrhea: a community trial in the rural areas of Saudi Arabia. J Trop Med Hyg 98: 126-130.

10. Cristofari M, Deshmukh A, Wang B (1996) Green quality function deploymnet Proceedings of the 4th International Conference on Environmentally Conscious Design and Manufacturing 297-304. Cleveland, Ohio.

11. Vinodh S, Chintha SK (2002)Application of fuzzy QFD for enabling sustainability. Int J Sustain Eng 4: 313-322.

12. Masui K (2003) Applying quality function deployment to environmentally conscious design. Int J Qual Reliabil Manag 20: 90-106.

13. Taguchi G (1986) Introduction to Quality Engineering: Design Quality into Products and Processes. Qua Resour Japan.

14. Isaksson R (2005) Economic sustainability and cost of poor quality. Corp Socia Resp Env Manag 12: 197-209.

15. Rogers P, de Silva R, Bhatia R (2002) Water is an economic good: How to use prices to promote equity, efficiency and sustainability. Water Pol 4: 1-17.

16. Farmani R, Walters G, Savic D (2005) Trade-off between total cost and reliability for any town water distribution network. J Water Res Plann Manag 131: 161-171.

17. Sorgvist $L$ (1997) Difficulties of measuring the cost of poor quality. Measuring Business Excellence 1: 38-40.

18. Akao Y (1990) QFD: Integrating Customer Requirements into Product Design Cambridge, MA: Productivity Press.

19. Bouchereau V, Rowlands $H$ (2000) Methods and techniques to help quality function deployment (QFD). Benchmarking: An Int J 7: 8-20.

20. National Institute of Standards \& Technology.

This article was originally published in a special issue, Decision Support for Sustainability Management handled by Editor(s). Dr. Amro M. Farid, Masdar Institute, United Arab Emirates. 